TITLE:

\title{
Contrasting cardiovascular mortality trends in Eastern Mediterranean populations: contributions from risk factor changes and treatments
}

\author{
AUTHORS: Julia Critchley ${ }^{1}$, Simon Capewell ${ }^{2}$, Martin O Flaherty ${ }^{2}$, Niveen Abu-Rmeileh ${ }^{3}$, Samer \\ Rastam ${ }^{4}$, Olfa Saidi ${ }^{5}$, Kaan Sözmen ${ }^{6}$, Azza Shoaibi ${ }^{3}$, Abdullatif Husseini ${ }^{7}$, Fouad Fouad ${ }^{4,8}$, Nadia \\ Ben Mansour ${ }^{5}$, Wafa Aissi ${ }^{5}$, Habiba Ben Romdhane ${ }^{5}$, Belgin Unal ${ }^{6}$, Piotr Bandosz ${ }^{2}$, Kathleen \\ Bennett ${ }^{9}$, Mukesh Dherani ${ }^{2}$, Radwan Al Ali ${ }^{4}$, Wasim Maziak ${ }^{4,10}$, Hale Arık ${ }^{6}$, Gül Gerçeklioğlu ${ }^{6}$, \\ Deniz Utku Altun ${ }^{6}$, Hatice Şimşek $^{6}$, Sinem Doganay ${ }^{6}$, Yücel Demiral ${ }^{6}$, Özgür Aslan ${ }^{6}$, Nigel \\ Unwin $^{11}$, Peter Phillimore ${ }^{12}$
}

On behalf of MedCHAMPS (all members listed at the end of the paper)

Correspondence: Julia Critchley; email: jcritchl@sgul.ac.uk

1. Professor of Epidemiology, Population Health Research Institute, St. George's, University of London, Cranmer Terrace, London SW17 ORE

2. Department of Public Health and Policy, University of Liverpool, UK

3. Institute of Community and Public Health, Birzeit University, oPt

4. Syrian Center For Tobacco Studies, Aleppo, Syria

5. Cardiovascular Epidemiology and Prevention Research Laboratory, Tunisia

6. Dept of Public Health, Faculty of Medicine, Dokuz Eylul University, Turkey

7. Public Health Program, Department of Health Sciences, Qatar University, Doha, Qatar

8. Department of Epidemiology and Public Health, American University of Beirut

9. Department of Pharmacology \& Therapeutics, Trinity College, Dublin, Ireland

10. Robert Stempel College of Public Health And Social Work, Florida International University, Miami, FI, US

11. Nigel Unwin, The Faculty of Medical Sciences, University of the West Indies, Barbados

12. Peter Phillimore, Institute of Health and Society, Newcastle University, UK 
Word counts:

Abstract: $\mathbf{2 5 0}$ words

Paper: $\mathbf{4 0 0 0}$ words,

Tables: 4 Figures: 3

Key words: cardiovascular mortality, risk factor, treatment, trend, model, Eastern Mediterranean 


\begin{abstract}
BACKGROUND

Middle income countries are facing an epidemic of non-communicable diseases, especially coronary heart disease (CHD). We used a validated CHD mortality model (IMPACT) to explain recent trends in Tunisia, Syria, the occupied Palestinian territory (oPt) and Turkey.
\end{abstract}

\title{
METHODS
}

Data on populations, mortality, patient numbers, treatments and risk factor trends from national and local surveys in each country were collated over two time points (1995-97; 200609); integrated and analysed using the IMPACT model.

\section{RESULTS}

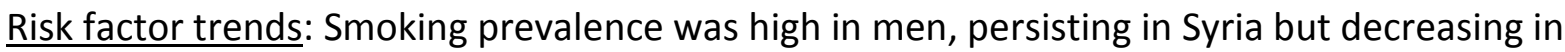
Tunisia, oPt and Turkey. BMI rose by $1-2 \mathrm{~kg} / \mathrm{m} 2$ and diabetes prevalence increased by $40 \%-50 \%$. Mean systolic blood pressure and cholesterol levels increased in Tunisia and Syria.

Mortality trends: Age-standardised CHD mortality rates rose by $20 \%$ in Tunisia and $62 \%$ in Syria. Much of this increase ( $79 \%$ and $72 \%$ respectively) was attributed to adverse trends in major risk factors, occurring despite some improvements in treatment uptake.

CHD mortality rates fell by $17 \%$ in oPt and by $25 \%$ in Turkey, with risk factor changes accounting for around $46 \%$ and $30 \%$ of this reduction respectively. Increased uptake of community treatments (drug treatments for chronic angina, heart failure, hypertension and secondary prevention after a cardiac event) accounted for most of the remainder. 


\section{DISCUSSION}

CHD death rates are rising in Tunisia and Syria, whilst oPt and Turkey demonstrate clear falls, reflecting improvements in major risk factors with contributions from medical treatments. However, smoking prevalence remains very high in men; obesity and diabetes levels are rising dramatically. 


\section{Introduction}

Coronary heart disease (CHD) is the most common cause of mortality globally, generating more than 7 million deaths each year. CHD is expected to remain a leading cause of death beyond $2030^{12}$. Different regions are at varying stages in their CHD epidemics. For example, after peaking in the 1960s, CHD mortality in Western countries has subsequently halved. Central European countries have experienced more recent and abrupt declines following socioeconomic transformations in $1989 / 1990^{3}$. The drivers of these CHD mortality trends are increasingly well characterised in affluent countries. Diverse studies generally suggested that risk factor improvements explain half to two thirds of the mortality declines with the remaining one third to half coming from evidence based treatments ${ }^{4-6}$. CHD and other non-

communicable diseases (NCDs) are increasing as a proportion of total mortality in most middle and low income countries ${ }^{127}$. However, much less information on the CHD burden (mortality, morbidity and costs) and CHD trends are available from these populations. This is particularly worrisome for countries in the Eastern Mediterranean Region, where predictions suggest substantial increases in the number of NCD deaths by $2020^{8}$. For countries in this region, there is therefore an urgent need to analyse local and regional CHD trends and quantify the impact of risk factors and treatments.

Risk factor trends across the WHO-EMRO region were recently summarised in GBD Lancet papers $^{9-12}$. However, such analyses risk portraying a relatively "homogenous" view of the region, whereas mortality trends are strikingly heterogeneous. For instance, our analyses show 
that CHD mortality is rising rapidly in many countries including Tunisia and Syria, but decreasing in other Mediterranean countries such as the occupied Palestinian territories and Turkey.

It is clearly important to identify trends in CHD mortality in low and middle income settings and appraise their variations between countries, so as to inform effective policies to reduce the future disease burden. Our aim was therefore to analyse recent CHD trends in Tunisia, Syria, occupied Palestinian territories (OPT, West Bank), and Turkey (middle income countries in the Eastern Mediterranean region), and assess the recent contribution of risk factor changes and evidence based treatments. These four countries were selected on the basis of a) data availability and quality, b) previous successful collaborations, some of which had resulted in substantial relevant data collection over time, and c) representing a range of economic development, population size, and absolute mortality rates across this region (see Tables 1 and 2). 


\section{Methods}

The socio-demographic and economic characteristics of the Tunisian, Syrian, oPt (West Bank), and Turkish populations are compared in Table 1.

\section{The IMPACT Model}

We used an updated version of the IMPACT CHD mortality model (Appendix 1). This has been employed and validated in a variety of countries from North America through Europe to China ${ }^{4}$

13. Data on risk factor levels and current uptake levels of evidence-based treatments were identified by extensive searches for published and unpublished data, and complemented where necessary with specifically designed surveys.

Data sources used to populate the model are detailed in Appendix 2 and in previous work ${ }^{14}$. In brief, they include:

a) Population and CHD mortality data (from national statistical agencies).

b) Patient numbers and uptake of specific medical and surgical treatments in nine CHD patient groups.

c) Population trends in major cardiovascular risk factors (smoking, total cholesterol, systolic blood pressure, body mass index, diabetes and physical inactivity).

In order to estimate trends, these data items were acquired for two time points (referred to as the initial and final years respectively). These were the most recent year with data available (final), and one 10-15 years previously (initial); 1997-2009 for Tunisia, 1996-2006 for Syria, 19982009 for oPt and $1995-2008$ for Turkey). Data were stratified by 10-year age groups and sex. Due to variations in data availability, there were some minor differences in the age groups included for each population (25+ in Tunisia and Syria; 25-74 in West Bank, oPt; 35-84 in Turkey). 


\section{Change in CHD deaths between the initial and final years}

The number of CHD deaths expected in the final year was calculated by applying the age and sex specific death rates in the initial year to the population age and sex structure in the final year. The observed $\mathrm{CHD}$ deaths in the final year were then subtracted to estimate the difference between the initial and final years. This was described as the number of deaths prevented or postponed (DPPs) if negative, or increased mortality if positive (the number the model attempts to explain in each country).

Data on patient numbers and treatment uptakes during the initial and final years were obtained for nine mutually exclusive CHD subgroups: patients hospitalized during that year for an acute myocardial infarction (AMI) or unstable angina pectoris (UAP) or heart failure due to CHD, community-dwelling patients who were post-AMI survivors, patients with chronic angina, patients receiving revascularisation ( $C A B G$ or $\mathrm{PCI}$ ), patients in the community with heart failure due to CHD (i.e. those treated outside of hospital), and individuals eligible for primary prevention being hypertensive (eligible for blood pressure lowering treatments) or having hypercholesterolaemia (eligible for lipid lowering therapy). These data, along with information on uptake levels of evidence based treatments were obtained from a combination of national statistics, local surveys, grey literature, hospital records and specifically designed surveys as appropriate (Appendix 2). These were used for estimating treatment coverage in the initial and final years. 
Data on trends in population risk factors (smoking prevalence, total cholesterol, systolic blood pressure, body mass index, diabetes) were obtained mainly from national and local surveys complemented by published and grey literature (Appendix 2).

\section{The mortality changes attributed to risk factor trends}

The deaths attributable to population changes in risk factor levels were estimated using one of two approaches.

The regression $\beta$ coefficient approach was used to quantify the population mortality impact of change in continuous risk factors (systolic blood pressure, total cholesterol and BMI). The mortality change was then estimated as the product of the CHD deaths observed in the initial year, the subsequent change in the risk factor, and the $\beta$ regression coefficient quantifying the change in CHD mortality expected per unit of absolute change in the risk factor (Appendix 1). These regression coefficients were derived from international studies after controlling for all other coefficients included in the model (see Appendix 1, eTable3). For example, the coefficient for $\mathrm{BMI}$ is independent of that for BP, cholesterol and Diabetes. They also control for the effects of increased treatment uptake (for lowering blood pressure and cholesterol levels) over time (see Appendix 1, page 7).

A second approach, population attributable risk fraction, was used for categorical variables- smoking, diabetes, and physical inactivity by applying Levin's formula (Appendix 1). Lag times between the change in cardiovascular risk factor levels and change in CHD mortality rates were assumed to be relatively rapid ${ }^{15-18}$ and were therefore not specifically modelled. 
CHD deaths are caused by multiple risk factors acting simultaneously. Enumerating mortality changes from risk factor trends should ideally therefore not use a simple additive approach. Instead, the effects of risk factor changes were jointly estimated using the cumulative riskreduction approach (a multiplicative approach). This can be stated in the equation:

$$
\text { Cumulative effect }=1-((1-a) *(1-b) *(1-c) * \ldots(1-n))
$$

Where $\mathrm{n}$ is the total number of additional risk factors (in this case 5 as in total we modelled 6 )

This cumulative effect of change in all risk factors over the study period was calculated by age and sex for each country (see Appendix 1, page 8-10). The ratio of the cumulative effect to the corresponding additive effect was then calculated, yielding 70 adjustment factors. These adjustment factors were used to scale down the additive DPPs for each risk factor. These adjusted DPPs, summed over all seven risk factors, then equalled the estimated total combined DPPs, capturing the multiplicative net impact of positive and adverse changes in risk factors. All risk factor DPPs quoted in the results tables refer to the adjusted DPPs.

\section{Estimating the mortality reduction attributable to medical and surgical treatments}

The model included all medical and surgical treatments for the nine mutually exclusive patient groups in both the initial and final years.

Case-fatality data were obtained from large, unselected, population-based patient cohorts. Survival benefit over a one-year time interval was used for all treatments, as we are only interested in quantifying deaths prevented or postponed for at least one year. (Appendix 1) 
The mortality reduction for each treatment was then calculated as the number of patients in each group, multiplied by the group age-sex-specific case fatality, the treatment uptake and the relative mortality reduction (efficacy). The efficacy of each therapeutic intervention was based on recent meta-analyses and randomised controlled trials. (Appendix 1, eTable 1)

The potential effect of multiple treatments in an individual patient was calculated conventionally using the Mant and Hicks cumulative relative benefit approach ${ }^{3}$.

Treatment adherence and overlaps (Appendix 1, page 7)

To avoid double counting, potential overlaps between different groups of patients were identified and adjusted. Adherence (the proportion of treated patients actually taking therapeutically effective levels of medication) was assumed to be $100 \%$ in hospital patients, $70 \%$ in symptomatic community patients, and $50 \%$ in asymptomatic community patients ${ }^{19-21}$.

\section{Sensitivity Analyses (Appendix 1, page 7)}

Similar to economic evaluation studies in health ${ }^{22}, 95 \%$ uncertainty intervals around the model output (i.e., DPPs) were calculated using Monte Carlo simulation. This calculation involved replacing all fixed input parameters used in the model by appropriate probability distributions, and repeatedly recalculating the model output with values sampled from the defined input distributions (see Appendix 1 Page 10 eTable 1). We used the EXCEL add-in Ersatz software (www.epigear.com) to perform 10,000 runs to determine the $95 \%$ uncertainty intervals of the DPPs (2.5th and 97.5th percentile values corresponding to the lower and upper limits). For clarity, the "best" estimates only are reported in the text and the "maximum" and "minimums" in Tables 3 and 4. 
Model validation: comparison with observed mortality falls

The model estimates for the total number of deaths prevented or increased by each risk factor change and each treatment were summed. These estimates were then compared with the observed changes in mortality in each age group for men and women. 


\section{Results}

\section{Mortality trends}

Age adjusted CHD mortality rates rose by $20 \%$ in Tunisia and by $62 \%$ in Syria during the observation period for each country. In contrast, age adjusted CHD mortality rates fell by $17 \%$ in oPt and by $29 \%$ in Turkey (Table 2, Figure 1).

These mortality trends resulted in approximately 680 additional deaths in Tunisia and some 6,370 additional deaths in Syria, in the final year compared with the initial year. The declines in mortality rates resulted in approximately 120 fewer deaths in oPt and 35,720 fewer deaths in Turkey (see Table 2; minimum and maximum estimates are detailed in Tables 3 and 4).

Large variations in CHD mortality trends were seen for men and women, with the relative changes generally favouring men, except in Tunisia (Table 2, Figures 2-3).

\section{Risk factor trends and associated mortality changes (Figure 2 and Table 3)}

SMOKING: Smoking prevalence decreased in all countries apart from Syria. Major changes were seen in Turkey; a fall of $-11 \%$ ( $41 \%$ relative reduction) followed by oPt $-10 \%$ ( $31 \%$ relative reduction). However smoking generally remained common among men (45\% to 59\% prevalence across the four countries). In Tunisian women, smoking prevalence doubled from $2 \%$ to $4 \%$, resulting in some 30 additional deaths in the final model year. In Syria, smoking increased in women from $10 \%$ to $15 \%$ generating approximately 100 additional deaths in the final year. In oPt smoking prevalence decreased by $14 \%$ among men and by $7 \%$ in women. In Turkey, there was a major reduction in smoking prevalence of $20 \%$ in men and $2 \%$ in women, accounting for over 7200 fewer CHD deaths in men and nearly 1200 fewer deaths in women (Table 3 and Appendix 3). 
SYSTOLIC BLOOD PRESSURE: Population mean systolic blood pressure (SBP) levels increased slightly in Tunisia $(+0.6 \mathrm{mmHg})$ and rose substantially in Syria $(+8.7 \mathrm{mmHg})$ but were broadly static in oPt and decreased in Turkey $(-2.6 \mathrm{mmHg})$.

Important differences were seen between men and women. In Tunisia, SBP increased on average by 4 $\mathrm{mmHg}$ for men (129 mmHg to $133 \mathrm{mmHg}$ ), whereas in women it fell by $2 \mathrm{mmHg}$ (131 mmHg to 129 $\mathrm{mmHg}$ ) - see Figures and Appendix 3. Similarly in oPt, average SBP decreased by $0.7 \mathrm{mmHg}$ in men while among women it increased by $0.7 \mathrm{mmHg}$.

The increase in SBP in Tunisia and Syria resulted in over 2,200 additional deaths according to our model estimates. The decrease in Turkey and oPt resulted in nearly 9,000 CHD fewer deaths in the two countries.

CHOLESTEROL: Cholesterol levels increased in both Syria $(+0.3 \mathrm{mmol} / \mathrm{l})$ and Tunisia $(+0.14 \mathrm{mmol} / \mathrm{l})$. In Turkey levels remained broadly constant $(+0.01 \mathrm{mmol} / \mathrm{l})$, and in oPt decreased by $0.06 \mathrm{mmol} / \mathrm{l}$.

There were different trends for men and women. In Tunisia, cholesterol increased by $0.73 \mathrm{mmol} / \mathrm{I}$ in men but decreased by $0.42 \mathrm{mmol} / \mathrm{l}$ in women. In Syria, cholesterol levels increased in both men and women ( 0.22 and $0.38 \mathrm{mmol} / \mathrm{l}$ respectively), and rose modestly in Turkey (by $0.01 \mathrm{mmol} / \mathrm{l}$ in men and women). In oPt, cholesterol levels decreased in men (-0.07 mmol/l) and women ($0.11 \mathrm{mmol} / \mathrm{I})$. Over 270 additional CHD deaths in Tunisia, 310 in Turkey and 1350 in Syria were attributable to the rises in cholesterol. The reduction in oPt resulted in approximately 40 fewer CHD deaths.

BMI: BMI rose substantially in all four countries, increases ranging from $1.4 \mathrm{~kg} / \mathrm{m}^{2}$ in Tunisia to $3 \mathrm{~kg} / \mathrm{m}^{2}$ in oPt. Absolute levels were much higher in women over the whole time period. BMI generally rose more among men than women (except in Syria where the increase was similar in 
men and women). More than 80 deaths in Tunisia, nearly 400 deaths in Syria, and over 3000 deaths in Turkey were attributed to this obesity rise (Table 3).

DIABETES: Diabetes prevalence also increased substantially in all four countries. Overall, a $43 \%$ relative increase was observed in Tunisia, $52 \%$ in Syria, $44 \%$ in oPt and $21 \%$ in Turkey. In general bigger increases were seen in men than in women. In Tunisia, diabetes prevalence increased more among men ( $12 \%$ to $19 \%)$ compared with women (12\% to 16\%). In Syria there was a similar relative increase in diabetes in men and women of $+52 \%$, but overall prevalence was higher in women ( $15 \%$ versus $11 \%$ in men). In oPt, the relative increases in diabetes were also around 2.5 times as much in men (+64\%) as in women (+26\%), In Turkey diabetes increased similar in men and women (+21\%).

Our model estimated that over 5,000 additional CHD deaths could be attributed statistically to the rising diabetes prevalence in the region (approximately 30 in oPt, 60 in Tunisia, 600 in Syria, and around 4,500 additional deaths in Turkey - Table 3).

PHYSICAL INACTIVITY: Trends in physical inactivity are particularly difficult to interpret and could not be estimated at all in Syria. The contribution of physical inactivity trends was in general small because available data suggested that physical activity levels were low and remained low over the time period of the study.

\section{Effect of adjusting for cumulative risk factor trends}

Adjusting for multiple risk factor trends occurring simultaneously reduced the proportion of the total mortality change that could be explained by risk factors significantly. In absolute terms, this was reduced by between 6 percentage points in Turkey (from 36\% to 30\%); 10 in oPt (from 
$56 \%$ to $46 \%$ ) to 18 in Syria (from $90 \%$ to $72 \%$ ) and 19 percentage points in Tunisia (from $98 \%$ to 79\%) to and age group, compared with a simpler additive model.

\section{Estimating the contribution of medical and surgical treatments}

The impact of other primary preventive therapies (mainly statins) was low except in Tunisia (Table 4a, Figure 3).

\section{Overall contribution of evidence based treatments and risk factors}

Overall treatment uptakes increased in all countries.

\section{a) in countries with increasing mortality rates (Tables $3 \& 4 a$ )}

Adverse trends in risk factors explained approximately $79 \%$ of the observed mortality rise in Tunisia and over $72 \%$ of the increase in Syria, after adjusting for the effects of cumulative risk factor changes. In effect, this means that between $21 \%$ of the rise in Tunisia and $28 \%$ in Syrian cannot be explained.

These mortality rises occurred in spite of improved treatment uptakes, resulting in approximately 450 fewer CHD deaths in Tunisia and some 2140 fewer deaths in Syria (Table 4a).

b) in countries with declining mortality rates (Tables $3 \& 4 b$ )

In the occupied Palestinian territories (oPt) risk factor changes explained more than $46 \%$ of the overall mortality fall with treatments accounting for approximately $32 \%$ and in Turkey the relative contribution was approximately $30 \%$ for risk factor reduction and $47 \%$ for increased 
treatment uptake (Table 3). This means that $22 \%$ of the decline was not explained in Turkey and $23 \%$ in oPt.

The largest medical contributions generally came from the community based treatments (treatment outside of hospital settings), particularly prescribing of aspirin and other secondary preventive medical therapies such as statins and anti-hypertensives after AMI, and community treatments for heart failure. In oPt and Turkey, hypertensive therapies also made important contributions.

\section{Model validation}

The IMPACT model has been replicated in over 15 countries worldwide, though most of these are high income countries. The model has also recently been validated for forward prediction in European populations ${ }^{23}$. The agreement for future projection was generally high (varying from $90 \%$ of $106 \%$ of expected deaths prevented or postponed, albeit over short periods of time 2324 . We assessed agreement between model estimates of the number of deaths prevented or postponed with official mortality statistics in these countries. The IMPACT Model estimates were apparently able to explain approximately $75 \%$ of the observed mortality changes in Turkey, and oPt, but less in Syria, and Tunisia respectively, although the fit depends on whether adjusted or unadjusted risk factor DPPs are combined, and whether risk factor and treatment trends are also summed (Tables 3 and 4, Appendix 4 Table 2). This may reflect that the model was originally developed for populations where CHD mortality is declining, or possibly reflect issues with data quality. However the model does not include trends in all CHD risk factors and hence $100 \%$ agreement would not be expected. 


\section{Discussion}

\section{Summary of main findings}

CHD mortality rates have dramatically risen in Tunisia and Syria, but have thankfully fallen in the occupied Palestinian territory (oPt) and Turkey. These mortality trends mainly reflect changes in major cardiovascular risk factors, moderately alleviated by treatment contributions. These treatment contributions appeared slightly greater in Tunisia and Turkey; this may reflect a stronger primary health care system in the latter case ${ }^{25}$, and higher uptake of effective medical therapies for secondary prevention after $\mathrm{AMI}$ or $\mathrm{CABG} / \mathrm{PCl}$ surgery. In Tunisia, uptake of initial treatments for AMI was also proportionately higher. Treatment contributions appeared weakest in Syria, probably reflecting a limited and deteriorating primary health care system (even before 2011$)^{25}$, though there was some prescribing of effective drug treatments for chronic angina and heath failure. In all four countries, BMI and hence diabetes was rising, and these adverse trends would have resulted in increases in CHD mortality of about 2-10\% and $10-20 \%$ respectively. However, trends in other risk factors were more heterogeneous. In Syria, smoking prevalence increased slightly (explaining 3\% of the upward trend) but in Turkey and oPt smoking prevalence fell substantially (explaining almost $25 \%$ of the reduction in mortality). Systolic blood pressure also fell in Turkey (explaining almost another $25 \%$ of the downward trend), possibly reflecting both increased prescribing of anti-hypertensives and falls in salt consumption ${ }^{26}$. Cholesterol levels declined slightly in oPt and were relatively flat in Tukey, but around $40 \%$ of the small increase in CHD mortality in Tunisia could be attributed statistically to rising cholesterol levels, and just over $20 \%$ in Syria. Overall, in the two countries with increases in CHD mortality, (Tunisia and Syria), the adverse risk factor trends explained most (70-80\% roughly) of the increase. In populations with falling CHD mortality rates, about one-third to half the decline was attributed to declines in major risk factors (smoking 
cholesterol and blood pressure), with another one-third to half attributed to increased uptake of effective medical and surgical treatments for CHD (see Appendix 4, Table 2). In some Western countries, the IMPACT model has been able to explain more of the mortality trends, but this may not be surprising given imperfect data. The data on risk factor changes generally came from high quality nationally representative studies using good valid measurement methods such as repeated BP measurements, fasting plasma glucose for diabetes, particularly in Tunisia. However in Syria and oPt some data was based on sub-regional studies which we had to assume were nationally representative, particularly at the earlier time point. Risk factor data and quality are addressed in more detail in another publication ${ }^{14}$ and appendix 3 . Routine data on treatment uptakes and trends was of more variable quality but we supplemented this by carrying out our own surveys and audits specifically for this project (see appendix 2 ). It is possible that our analyses may slightly over-estimate the treatment contributions, since hospitals that take part in such studies are more likely to be tertiary referral centres, and may hence be performing better than other secondary centres, although we adjust for this factor in probabilistic sensitivity analyses. We would also acknowledge that treatment data from the first time point (in the mid-1990s) were more uncertain and limited. However, this does not greatly influence model estimates since very little in the way of effective medical or surgical treatments were available in any of the 4 populations at the beginning of the model period. Death certification data is more variable in quality in low and middle income countries. Reassuringly, there has been no change in completeness of Tunisian death certification over this time period which could bias our results ${ }^{28}$, and death certification data from oPt was classed as "medium" quality according to WHO criteria ${ }^{29}$. In Turkey, analyses of causes of death from a previous national burden of disease study were used to adjust death certification estimates $^{30}$. Whilst there are concerns about national death registry deaths in Syria, we used alternative sources (the Aleppo Household survey) ${ }^{31}$, which we considered more valid albeit at 
the possible cost of generalisability.The diverging trends powerfully emphasise that regions should not be treated homogeneously ${ }^{32}$. Previous Global Burden of Disease analyses ${ }^{33}$ projected specific risk factor trends against the levels and changes in wealth and urbanisation in around 100 developing countries. For example, with increasing affluence both obesity and cholesterol levels tend to increase. Our study shows that CHD death rates are rising in Tunisia and even more substantially in Syria (prior to the current conflict), the poorest of the four countries (Gross National Income in International Dollars (Purchasing Power Parity) GNI I\$ 4,010 in 2005, and compared with Tunisia (GNI 6,820). By contrast, Turkey, with a far higher GNI of 11,330 demonstrated clear mortality falls. Furthermore, all four populations experienced substantial increases in BMI, with Syria showing the greatest increase, and Turkey the least.

The occupied Palestinian territory (oPt) appears an interesting outlier, with slight cholesterol falls (and generally favourable risk factor trends) despite apparently very modest levels of wealth and the lowest GNI of the four (GNI I\$2,710). However, there are known difficulties in estimating GNI for the $\mathrm{OPt}^{34}$. The mortality falls may reflect substantial international donations, high levels of education and literacy and a relatively well developed public health system ${ }^{35}{ }^{36}$, partly facilitated by a small population size. Furthermore, it suggests that CHD mortality trends cannot simply be predicted by levels of economic development.

Perhaps most critical in explaining differences across the region are the smoking levels and trends. Smoking prevalence remained very high in men in Syria and Tunisia but declined in Turkey and oPt. Although smoking is relatively uncommon among women in Tunisia and Syria, both may be underreported (particularly as most national sources are self-reported) and there are also worrying signs that it may be increasing, particularly in younger people ${ }^{37}$.

Different trends were seen for obesity between men and women. Although greater increases in BMI were observed in men, mean BMI remains much higher in women, particularly in Syria and 
Tunisia. The high levels of female obesity presumably reflect traditional gender roles, gender inequality, and limited opportunities for women to leave the home environment (and partake in any physical activity). Data on physical activity are seriously limited across the region; however a recent Tunisian survey ${ }^{38}$ demonstrated very low levels of female participation in regular exercise of any kind. Trends in other risk factors were broadly similar by gender.

\section{Dietary trends}

Rapid risk factor and mortality changes observed in this study clearly reflect substantial economic and nutritional transitions in the Middle East. A dramatic rise in per capita energy and fat supplies in most countries has occurred over the past four decades. For example, between 1971 and 1997, calorie intakes rose by over 40\% in Syria and Tunisia, (from 2,340 to 3,350 calories in Syria and from 2,280 to 3,280 calories in Tunisia) ${ }^{39}$. Fat intakes similarly increased by over $60 \%$ over the same time period ${ }^{39}$. Sugar consumption may also have risen ${ }^{39-}$ 41, whilst intakes of fruit, vegetables and fibre have all fallen ${ }^{39}$. The high calorie intakes, and limited physical activity have resulted in particularly high obesity rates, and hence escalating diabetes prevalence in this region. Sodium intake is also high, thereby increasing blood pressure ${ }^{26}$. Rapidly increasing urbanisation probably underlies some of the dietary trends, with increased availability of processed foods, and possibly compounded by lower requirements for routine physical activity. In Turkey for example, between 1988 and 2008 the proportion of the population dwelling in urban areas increased from $25 \%$ to $75 \%$.

\section{Methodological adjustment for cumulative risk factor trends}

The methodological refinement in this paper, accounting for multiple risk factor trends occurring simultaneously, significantly affected the proportion of the mortality trend that could be attributed to individual risk factor changes, reducing it by up to nearly $20 \%$ compared with 
previous analyses. This contrasts with a previous study which did not demonstrate significant differences between these two approaches in a UK setting ${ }^{34}$. This difference may reflect the rapid risk factor trends that have been observed in the middle income countries in this study, and suggests that this refinement is most critical in countries in transition, undergoing rapid epidemiological changes. However, most current global modeling studies that attribute mortality trends to specific risk factor trends do not generally use a cumulative approach. Our study thus provides evidence of the importance of specific modeling approaches in this context, as well as original data for this under-researched region.

\section{Increasing uptake of evidence-based treatments}

Some favourable trends in the uptake of effective treatments have occurred, particularly in oPt and Turkey. The major contributors were improved uptake of aspirin and other secondary prevention medications, plus community heart failure treatments. Although the patterns were broadly similar there were some important differences between countries. For instance Tunisia had a much higher uptake of statins for primary prevention, but in other populations these uptakes remained low at the end of our period of analysis (approximately 2008), suggesting significantly greater potential with increasing use in the future ${ }^{42}$. Simple, accepted drug regimens or combinations (generally including aspirin, a calcium channel blocker, ACE inhibitor and statin) may be cost-effective for CHD patients even in low income settings and merit further study ${ }^{43}$. However, treatment uptakes are still generally very low ${ }^{45}$ emphasising the remaining potential for cheap, effective medical therapies to help reduce CHD mortality rates. 
Modelling studies have a number of potential strengths, providing integration and simultaneous consideration of large amounts of data. The IMPACT Model has been widely used to explain CHD mortality trends, and has now been validated in over 15 high income populations ${ }^{34}$. However, this is the first analysis of middle income populations in the Middle East.

We acknowledge many limitations. All models are dependent on the quality and extent of data available, and the outcome data (CHD mortality) is particularly important. Mortality trends by cause of death remain uncertain in many low and middle income countries due to incomplete or inaccurate coding, and a lack of trend data. Global Burden of disease analyses highlight the significant declines in adult mortality seen in many low and middle income countries in recent decades $^{46}$. Life expectancy has risen in all 4 populations, but this is driven mainly by substantial declines in infant mortality ${ }^{47}$. As $\mathrm{CHD}$ is a major component of total mortality, this might lead us to expect that age-specific CHD mortality is also falling globally. However, our data from Syria and Tunisia demonstrated increasing age-specific CHD mortality in recent years. In support of our findings, major CHD risk factors (smoking, blood pressure, and blood cholesterol) which together account for about $85 \%$ of variation in CHD mortality ${ }^{48}$ were either stagnant or increased in Syria and Tunisia over this time period; no substantial decreases were observed. Reassuringly, there has been no change in completeness of Tunisian death certification over this time period which could bias our results ${ }^{28}$, and whilst there are concerns about national death registry deaths in Syria, we used alternative sources (WHO and the Aleppo Household survey). A picture of continued adult mortality decline is by no means clear cut since other authors using the Demographic and Health surveys suggest that mortality decline has recently flattened in some MENA countries (Jordan, Yemen and Morrocco) ${ }^{49}$. Further, an increases in age-specific CHD mortality has also recently been reported in the largest country in this region (Egypt $\left.{ }^{46}\right)$. Hence our detailed analyses by country highlight the heterogeneity in cause of death trends among middle income countries. The Middle East 
suffers particularly high male smoking rates and very low levels of physical activity; BMI and diabetes have been increasing faster than elsewhere in the world.

Overall, the IMPACT model apparently explained up to $77 \%$ of the mortality trend observed in each country. This appears acceptable, particularly considering the variable death certification and imperfect risk factor measurement across the region.

The model itself makes many simplifying assumptions. First it ignores potential lag times between changes in a risk factor and change in mortality, however, evidence suggests that lag times can be very short in practice ${ }^{15-18}$. It assumes a log-linear association between risk factors and CHD mortality; and the regression approach implicitly assumes that other, unmeasured risk factors have not changed over the model time period. This is not likely to be the case in practice. It assumes that trial estimates (efficacy) of medical and surgical treatments can be realised in practice; however, it does account for variable uptake and compliance of treatments. Estimates of one-year case-fatality had to be obtained from international rather than national sources and are thus uncertain (see eTable 3). We did not explicitly consider competing risks. However, reductions in smoking prevalence (in Turkey and oPt) should also reduce death rates from common cancers and respiratory diseases. Increases in BMI and diabetes however might also increase risk of deaths from diabetes or cancers. The model does account for changes in age structure over time, which are small over this relatively short time period. The data itself are only available at the population level. The model itself is thus essentially ecological in nature. However, we only include treatments and risk factors where there is strong evidence of a causal relationship with CHD mortality.

Naturally, data availability was variable across the countries involved. We populated the models with "national level" data or data from surveys covering a range of representative areas (such as in Turkey). Most of the major risk factors were measured rather than self-reported e.g. 
BMI was measured as height and weight, SBP and total cholesterol and diabetes were also measured using appropriate blood pressure monitors and blood tests. Smoking status is usually self-reported in surveys. While generally considered valid, this could result in an underestimate of smoking status, particularly among women in countries like Tunisia, where female smoking is still culturally frowned upon ${ }^{50}$. Physical inactivity is also self-reported, and could be less reliable. Using national level or regional data may also conceal important heterogeneity within

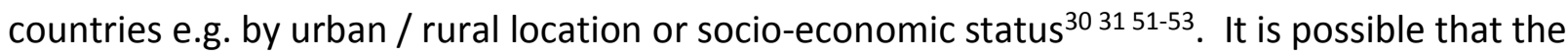
relative contribution to CHD mortality trends from increased treatment uptake could be lower in some poorer, rural regions where health insurance coverage is lower and services weaker. For example, situational analyses of NCD clinics, a separate part of this EC funded project, found that both patient record keeping and staff skills were weaker in poorer rural areas, and along with inadequate referral arrangements, could potentially lead to poorer treatment outcomes ${ }^{25}$.

Our model explains change in mortality over time, rather than the absolute levels. Whilst trends within the four countries are considered reliable (Appendix 2), comparisons between them should be made cautiously, due to potential differences in coding practices and quality of death certification. The model probably captures all major contributions to mortality change, but the contributions of each component have substantial uncertainty. However, probabilistic sensitivity analysis demonstrated that the relative contributions of risk factor changes and treatments to the overall mortality trends were reasonably consistent.

The current model only reports on mortality. Other outcomes (incidence, life years gained or lost, and cost-effectiveness) though potentially valuable ${ }^{54}$ would require further data which is not readily available in the region. However this merits attention in future work.

\section{Policy Implications}


Our results may be cautiously generalisable to other low and middle income populations, especially in the Eastern Mediterranean region (recognising the many potential similarities in social, cultural and economic attributes of these societies). It also highlights both the challenges (missing data) and benefits (identifying potential heterogeneity and effects of individual treatments) of grounding analysis in country-specific data, compared with other approaches. Clearly, the political catastrophe that has engulfed Syria since 2011 inevitably reduces the immediate relevance of the lessons that may be drawn from our Syrian findings; however, in the longer term these may provide a baseline for subsequent policy analysis and future policy development in a post-conflict era.

Our findings highlight the consistently powerful effects of even small changes in the major cardiovascular risk factors, smoking, blood pressure and cholesterol. Furthermore, dramatic rises in diabetes have occurred across the region, mainly reflecting marked increases in $\mathrm{BMI}$ and adverse trends in diet (particularly salt, sugar, saturated fat and calorie intakes). These dietary and obesity trends also underlie most of the observed increases in blood pressure and cholesterol levels.

These current adverse risk factor trends are very worrying and represent a clear wake-up call. They justify stronger regional and global policy responses targeting smoking, unhealthy diet, and physical inactivity. Effective interventions exist 5556 57-59; but their implementation may be politically challenging across diverse cultures. However, our analysis clearly demonstrates different trends across the countries, suggesting that national policies should perhaps be tailored to local priorities. Countries such as oPt and Turkey have performed relatively well on reducing SBP, cholesterol and smoking (despite on-going political difficulties). Neighbouring countries might therefore perhaps consider similar policies. Mortality trends broadly reflect 
changes in risk factors more than improved treatment uptake. In countries with wellestablished primary health care systems, medications may provide a useful strategy in addition to population-based interventions. Yet, whilst appropriately targeted medical interventions can be cost-effective, they may be difficult to implement, especially in countries without comprehensive primary health care. Population based policy interventions to reduce risk factors can also be challenging to implement and enforce, and the evidence base for reducing obesity and diabetes in low and middle income countries is sparse. However, evidence from other countries suggests that tobacco control and dietary policies can be powerful, rapid and cost saving. 555660,6162 These evidence-based policy interventions should therefore be strongly recommended for the prevention of both $\mathrm{CHD}$ and other non-communicable diseases. 
Acknowledgements: We thank Pat Barker for administrative assistance.

This study was funded by the European Community's Seventh Framework Programme (FP7/2007-2013) under grant agreement $n^{\circ} 223075$ - the MedCHAMPS project. MOF was also supported by the UK MRC.

This publication was prepared with support from and on behalf of the MedCHAMPS consortium members:

Nourredine Achour15, Waffa Aissi5, Riadh Allani5, Chokra Arfa5, Heidar AbuKteish ${ }^{13}$, Niveen Abu-Rmeileh ${ }^{3}$ Radwan Al Ali, Deniz Altun ${ }^{4}, B^{4}$,sam Ahmad ${ }^{9}$, Hale Arık6, Özgür Aslan6, Latifa Beltaifa5, Nadia Ben Mansour ${ }^{5}$, Kathleen Bennett7, Habiba Ben Romdhane5, Nabil Ben Salah"19, Marissa Collins'16, Julia Critchley ${ }^{1}$, Simon Capewel12, Mukesh Dherani², Yücel Demiral6, Sinem Doganay6, Madonna Elias4, Gül Ergör6, Ibtihal Fadhil18, Fouad Fouad4, Gül Gerçeklioğlú, Rula Ghandour ${ }^{3}$, Sibel Göğen ${ }^{11}$, Abdullatif Husseini3 ${ }^{3}$ Samer Jaber ${ }^{3}$, Sibel Kalaca12, Rana Khatib33, Rasha Khatib ${ }^{3}$, Saer Koudsie, Bülent Kilic ${ }^{6}$, Olfa Lassoued5, Helen Mason'16, Wasim Maziak4,8, Maher Abou Mayaleh"14, Nahed Mikki³, Ghmaez Moukeh4, Martin O Flaherty², Peter Phillimore9, Samer Rastam, Gojka Roglic ${ }^{17}$, Olfa Saidi ${ }^{5}$, Gül Saatli6, Ilhan Satman ${ }^{10}$, Azza Shoaibi ${ }^{3}$ Hatice Şimşek ${ }^{6}$, Nesrien Soulaiman', Kaan Sözmen', Faten Tlili5, Belgin Unal6, Nigel Unwin ${ }^{20}$, Nazan Yardim ${ }^{11}$, Shahaduz Zaman ${ }^{9}$.

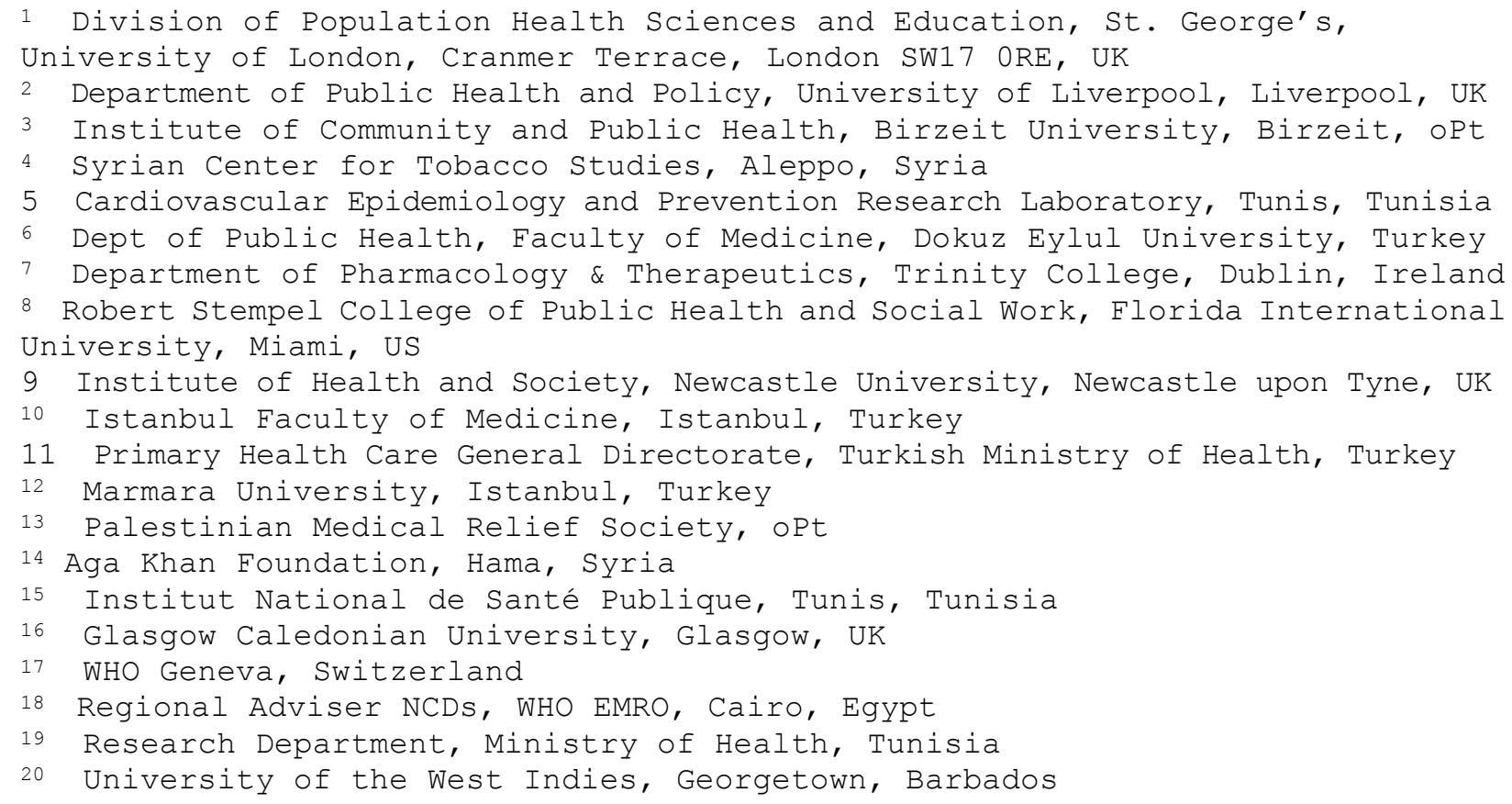

\section{Author contributions}

$J C$ and $S C$ conceived the idea of the study, and JC obtained the funding. MOF led the project supervised by SC and JC. SR, OS, NAR, KS, NBM, AS, RAA, BU, HA, GG, DUA, HS, SD, YD, OA assembled the datasets; extracted the data and populated the models with input from $F F, W M, H B R, B U, A H, S C, M o F, J C, K B, P P$, and NU. SC, MDh and JC wrote the first draft of the paper, and JC finalised the manuscript. All authors contributed to the analysis, intellectual content, critical revisions to the drafts of the paper and approved the final version. SC is the guarantor. 
Funding sources:

The MedCHAMPS project and data collection were funded by EC FP7 grant no. 223705. JC and SC are supported by the UK Higher Education Funding Council. MOF was partly funded by the European Union and the UK Medical Research Council.

Role of the funding source:

The funders had no role in study design, data collection and analysis, decision to publish, or preparation of the manuscript. The MedCHAMPS team had access to all data sources and has the responsibility for the contents of the report and the decision to submit for publication.

Ethical approval:

None required as secondary analysis of publicly available data

\section{Competing interest declaration:}

All authors have completed the Unified Competing Interest form at icmje.org/coi_disclosure.pdf (available on request from the corresponding author) and declare that (1) all authors had project support from EU funding; (2) no authors have a relationships with EU that might have an interest in the submitted work in the previous 3 years; (3) their spouses, partners, or children have no financial relationships that may be relevant to the submitted work; and (4) all authors have no non-financial interests that may be relevant to the submitted work.

Data sharing:

Supplementary appendices (attached) available with open access from the corresponding author.

\section{Abbreviations}

AMI: Acute Myocardial Infarction; BMI: Body mass index; CABG: Coronary Artery Bypass Graft; CHD: Coronary heart disease; DPP: deaths prevented or postponed; MI: Myocardial Infarction; PCI: Percutaneous Coronary Intervention; SBP: Systolic blood pressure. 


\section{References}

1. Mathers CD, Loncar D. Projections of Global Mortality and Burden of Disease from 2002 to 2030. PLoS Med 2006;3(11):e442.

2. Gaziano T, Bitton A, Anand S, Abrahams-Gessel S, Murphy A. Growing epidemic of coronary heart disease in low- and middle-income countries. Curr Probl Cardiol 2010;35(2): 72-115.

3. Bandosz P, O'Flaherty M, Drygas W, Rutkowski M, Koziarek J, Wyrzykowski B, et al. Decline in mortality from coronary heart disease in Poland after socioeconomic transformation: modelling study. BMJ 2012;344.

4. Ford ES, Ajani UA, Croft JB, Critchley JA, Labarthe DR, Kottke TE, et al. Explaining the decrease in U.S. deaths from coronary disease, 1980-2000. The New England journal of medicine 2007;356(23):2388-98.

5. Capewell S, Beaglehole R, Seddon M, McMurray J. Explanation for the decline in coronary heart disease mortality rates in Auckland, New Zealand, between 1982 and 1993. Circulation 2000;102(13):1511-16.

6. Hunink MGM, Goldman L, Tosteson ANA, Mittleman MA, Goldman PA, Williams LW, et al. The recent decline in mortality from coronary heart disease, 1980-1990. JAMA $1997 ; 277(7): 535$.

7. Anand SS, Yusuf S. Stemming the global tsunami of cardiovascular disease. The Lancet 2011;377(9765):529-32.

8. World Health Organization. Global status report on noncommunicable diseases 2010. Geneva, 2011.

9. Danaei G, Finucane MM, Lin JK, Singh GM, Paciorek CJ, Cowan MJ, et al. National, regional, and global trends in systolic blood pressure since 1980: systematic analysis of health examination surveys and epidemiological studies with 786 country-years and 5. 4 million participants. Lancet $2011 ; 377(9765): 568-77$.

10. Finucane MM, Stevens GA, Cowan MJ, Danaei G, Lin JK, Paciorek CJ, et al. National, regional, and global trends in body-mass index since 1980: systematic analysis of health examination surveys and epidemiological studies with 960 country-years and $9 \cdot 1$ million participants. Lancet $2011 ; 377(9765): 557-67$.

11. Farzadfar F, Finucane MM, Danaei G, Pelizzari PM, Cowan MJ, Paciorek CJ, et al. National, regional, and global trends in serum total cholesterol since 1980: systematic analysis of health examination surveys and epidemiological studies with 321 country-years and 3. 0 million participants. Lancet $2011 ; 377(9765): 578-86$.

12. Danaei G, Finucane MM, Lu Y, Singh GM, Cowan MJ, Paciorek CJ, et al. National, regional, and global trends in fasting plasma glucose and diabetes prevalence since 1980: systematic analysis of health examination surveys and epidemiological studies with 370 country-years and $2 \cdot 7$ million participants. Lancet 2011;378(9785):31-40.

13. Unal B, Critchley J, Capewell S. Explaining the decline in coronary heart disease mortality in England and Wales, 1981-2000. Circulation 2004;109:1101-07.

14. Sözmen K, Ünal B, Saidi O, Ben Romdhane H, Abu-Rmeileh N, Husseini A, et al. Cardiovascular risk factors trends in the Eastern Mediterranean region : Evidence from four countries is alarming. Int J Pub Health (accepted) 2014.

15. Kuulasmaa K, Tunstall-Pedoe H, Dobson A, Fortmann S, Sans S, Tolonen H, et al. Estimation of contribution of changes in classic risk factors to trends in coronary-event rates across the WHO MONICA Project populations. Lancet $2000 ; 355(9205): 675-87$.

16. Critchley J, Liu J, Zhao D, Wei W, Capewell S. Explaining the increase in coronary heart disease mortality in Beijing between 1984 and 1999. Circulation 2004;110(10):1236-44.

17. Zatonski WA, MCMichael AJ, Powles JW. Ecological study of reasons for sharp decline in mortality from ischaemic heart disease in Poland since 1991. BMJ $1998 ; 316(7137): 1047$.

18. Dowse G, Gareeboo H, Alberti K, Zimmet P, Tuomilehto J, Purran A, et al. Changes in population cholesterol concentrations and other cardiovascular risk factor levels after five years of the non-communicable disease 
intervention programme in Mauritius. British Medical Journal $1995 ; 311(7015): 1255$.

19. Fitz-Simon N, Bennett K, J. F. A review of studies of adherence with antihypertensive drugs using prescription databases. Therapeutics and Clinical Risk Management $2005 \quad 1(2): 93-106$.

20. Esposti LD, Saragoni S, Benemei S, Batacchi P, Geppetti P, Di Bari M, et al. Adherence to antihypertensive medications and health outcomes among newly treated hypertensive patients. ClinicoEconomics and Outcomes Research $2011 ; 3: 47-54$.

21. Jackevicius CA, Mamdani M, JV T. Adherence With Statin Therapy in Elderly Patients With and Without Acute Coronary Syndromes. JAMA 2002;288 (4) : 462-7.

22. Barendregt JJ. The effect size in uncertainty analysis. Value in health : the journal of the International society for Pharmacoeconomics and outcomes Research 2010;13(4):388-91.

23. Euroheart II project. CHD mortality projections to 2020, comparing different policy scenarios. Euroheart II Work $\quad$ Package 6. 2014 ; http: //www.ehnheart.org/euroheart-ii/euroheart-ii-

publications/publication/787-chd-mortality-projections-to-2020-comparingdifferent-policy-scenarios.html.

24. Hughes J, Kabir Z, Bennett K, Hotchkiss JW, Kee F, Leyland AH, et al. Modelling Future Coronary Heart Disease Mortality to 2030 in the British Isles. PLoS ONE 2015;10(9):e0138044.

25. Phillimore P, Zaman S, Ahmad B, Shoaibi A, Khatib R, Husseini A, et al. Health system challenges of cardiovascular disease and diabetes in four Eastern Mediterranean countries. Global public health 2013;8(8):875-89.

26. Erdem Y Fau - Arici M, Arici M Fau - Altun B, Altun B Fau - Turgan C, Turgan C Fau - Sindel S, Sindel S Fau - Erbay B, Erbay B Fau - Derici U, et al. The relationship between hypertension and salt intake in Turkish population: SALTURK study. (1651-1999 (Electronic)).

27. Türkiye'de tuz tüketimi çalışması SALTURK2. http://www.turkhipertansiyon.org/ppt/SALTurk2.ppt last accessed 27.03.2015), 2012 .

28. Murray CJL, Rajaratnam JK, Marcus J, Laakso T, Lopez AD. What Can We Conclude from Death Registration? Improved Methods for Evaluating Completeness. PLoS Med 2010;7(4): 7(4): e1000262. doi:10.1371/journal.pmed.62.

29. Abu-Rmeileh NME, Husseini A, Abu-Arqoub O, Hamad M, R. G. Mortality patterns in the West Bank, Palestinian Territories, 1999-2003. Prev Chronic Dis 2008;5(4) ):http://www.cdc.gov/pcd/issues/2008/oct/07 0184.htm. Accessed [07/10/2015].

30. Unal B, Sözmen K, Arık H, G. G, Altun DU, Simşek H, et al. Explaining the decline in coronary heart disease mortality in Turkey between 1995 and 2008. BMC Public Health 2013;13(1135).

31. Rastam S, Al Ali R, Fouad F, Maziak W, O'Flaherty M, Capewell S. Explaining the increase in coronary heart disease mortality in syria between 1996 and 2006. BMC Public Health 2012;12(754).

32. Mirzaei M, Truswell AS, Taylor R, Leeder SR. Coronary heart disease epidemics: not all the same. Heart 2009;95(9):740-46.

33. Ezzati M, Oza S, Danaei G, Murray CJL. Trends and Cardiovascular Mortality Effects of State-Level Blood Pressure and Uncontrolled Hypertension in the United States. Circulation 2008;117(7):905-14.

34. Bajekal M, Scholes S, Love H, Hawkins N, O'Flaherty M, Raine R, et al. Analysing recent socioeconomic trends in coronary heart disease mortality in England, 2000-2007: a population modelling study. PLoS Medicine $2012 ; 9(6): e 1001237$.

35. Giacaman R, Khatib R, Shabaneh L, Ramlawi A, Sabri B, Sabatinelli G, et al. Health status and health services in the occupied Palestinian territory. The Lancet;373(9666):837-49.

36. Rahim HFA, Wick L, Halileh S, Hassan-Bitar S, Chekir H, Watt G, et al. Maternal and child health in the occupied Palestinian territory. The Lancet; 373 (9667): 967-77.

37. El-Awa F, Warren CW, Jones NR. Changes in tobacco use among 13-15 year olds between 1999 and 2007: findings from the Eastern Mediterranean Region. EMHJ 2010;16(3):266-73. 
38. Ben Romdhane HAHUP, 2009. Pour une urbanisation saine de la ville de l'Ariana. Enquête auprès des ménages. Octobre 2010. Ariana Healthy Urbanization Project, 2009. Pour une urbanisation saine de la ville de l'Ariana. Enquête auprès des ménages. Octobre 2010, 2010.

39. Musaiger AO. Diet and Prevention of Coronary Heart Disease in the Arab Middle East Countries. Medical Principles and Practice 2002;11 (Suppl. 2):9-16.

40. National Institute of Statistics Tunisia. Trend of sugar consumption in Tunisia. Tunis: Habiba Ben Romdhane (personal communication), 2010.

41. Basu S, McKee M, Galea G, Stuckler D. Relationship of soft drink consumption to global overweight, obesity, and diabetes: a cross-national analysis of 75 countries. Am J Public Health 2013;103(11):2071-7.

42. Vancheri F. Trends in coronary heart disease mortality and statin utilization in two European areas with different population risk levels: Stockholm and Sicily. International Cardiovascular Forum Journal 2015;1(3):140-46.

43. Gaziano TA, Opie LH, Weinstein MC. Cardiovascular disease prevention with a multidrug regimen in the developing world: a cost-effectiveness analysis. The Lancet $2006 ; 368$ (9536):679-86.

44. Ortegón M, Lim S, Chisholm D, Mendis S. Cost effectiveness of strategies to combat cardiovascular disease, diabetes, and tobacco use in sub-Saharan Africa and South East Asia: mathematical modelling study. BMJ 2012;344.

45. Yusuf S, Islam S, Chow CK, Rangarajan S, Dagenais G, Diaz R, et al. Use of secondary prevention drugs for cardiovascular disease in the community in high-income, middle-income, and low-income countries (the PURE Study): a prospective epidemiological survey. The Lancet 2011;378(9798):1231-43.

46. Finegold JA, Asaria P, Francis DP. Mortality from ischaemic heart disease by country, region, and age: Statistics from World Health Organisation and United Nations. International journal of cardiology 2013;168(2):934-45.

47. Global, regional, and national age-sex specific all-cause and cause-specific mortality for 240 causes of death, 1990-2013: a systematic analysis for the Global Burden of Disease Study 2013. The Lancet;385(9963):117-71.

48. Emberson JR, Whincup PH, Morris RW, Walker M. Re-assessing the contribution of serum total cholesterol, blood pressure and cigarette smoking to the aetiology of coronary heart disease: impact of regression dilution bias. European heart journal 2003;24(19):1719-26.

49. De Walque D, Filmer D. Trends and Socioeconomic Gradients in Adult Mortality around the Developing World. Population and Development Review 2013;39 (1):129.

50. Research Laboratory of Epidemiology and Cardiovascular Diseases Prevention. Epidemiological Transition and Health Impact in North Africa TAHINA project Final Report. Tunis, 2006.

51. Abu-Rmeileh N, Shoaibi A, O'Flaherty M, Capewell S, Husseini A. Analysing falls in Coronary Heart Disease Mortality in the West Bank between 1988 and 2009 BMJ Open 2012; Under consideration(2): 4.

52. Saidi O, Ben Mansour N, O’Flaherty M, Capewell S, Critchley J, Ben Romdhane H. Analyzing recent coronary heart disease mortality trends in Tunisia between 1997 and 2009. Plos One 2013;DOI: 10.1371/journal.pone.0063202.

53. Dinc G, Sozmen K, Gerceklio Lu G, Ar KH, Critchley J, Unal B. Decreasing trends in cardiovascular mortality in Turkey between 1988 and 2008 . BMC Public Health 2013;13(1):896.

54. Gouda HN, Critchley J, Powles J, Capewell S. Why choice of metric matters in public health analyses: a case study of the attribution of credit for the decline in coronary heart disease mortality in the US and other populations. BMC Public Health 2012;12:88.

55. IOM (Institute of Medicine). Promoting Cardiovascular Health in the Developing World. A Critical Challenge to Achieve Global Health. In: Fuster V, Kelly B, editors. Washington DC: The National Academies Press, 2010.

56. National Institute for Health and Clinical Excellence. Prevention of cardiovascular disease at population level. NICE Public Health Guidance. London: National Institute for Health and Clinical Excellence, 2010.

57. Beaglehole R, Bonita R, Horton R, Adams C, Alleyne G, Asaria P, et al. Priority actions for the non-communicable disease crisis. The Lancet $2011 ; 377(9775): 1438-47$. 
58. El Awa F. The WHO Framework Convention on Tobacco Control as a tool for advancing health promotion: perspective from the Eastern Mediterranean Region. Glob Health Promot 2010;17 (1 Suppl):60-6.

59. Fong GT, Cummings KM, Shopland DR. Building the evidence base for effective tobacco control policies: the International Tobacco Control Policy Evaluation Project (the ITC Project). Tob Control 2006;15 Suppl 3:iiil-2.

60. Sassi F. Obesity and the Economics of Prevention. Fit not Fat: Organisation for Economic Co-operation and Development (OECD), 2010.

61. Murray CJL, Lauer JA, Hutubessy RCW, Niessen L, Tomijima N, Rodgers A, et al. Effectiveness and costs of interventions to lower systolic blood pressure and cholesterol: a global and regional analysis on reduction of cardiovascular-disease risk. The Lancet 2003;361(9359):717-25.

62. Gaziano $\mathrm{T}$, et al. Tax on salt and voluntary industry reductions in salt content could reduce deaths from cardiovascular disease by 3 percent in developing countries. Preliminary data from new Harvard report. World Congress of Cardiology. Dubai: World Heart Federation, 2012. 


\section{Tables}

Table 1. Socio-demographic and economic comparisons of the four Eastern Mediterranean countries.

Table 2. Crude CHD mortality rates and trends in the four Eastern Mediterranean countries

Table 3. Risk factor trends and consequent mortality changes in the four countries

Table 4a: Treatment contributions: numbers of patients in specific groups and CHD deaths prevented of postponed in Tunisia and Syria where CHD mortality was rising (men and women combined)

Table 4b: Treatment contributions: numbers of patients in specific groups and CHD deaths prevented of postponed in the oPt and Turkey where CHD mortality was falling (men and women combined)

\section{Figures}

Figure 1. Age-standardised CHD mortality rates and trends in the four Eastern Mediterranean countries (initial year and final year)*

Figure 2. Proportion of deaths (increasing or decreasing) attributed to changes in major risk factors, (by country and sex)

Figure 3. Proportion of deaths prevented or postponed attributable to increased uptake of specific treatments (by country and sex ). 
Table 1:

Socio-demographic and economic comparison of the four Eastern Mediterranean countries

\begin{tabular}{|lllll|}
\hline Country & $\begin{array}{l}\text { Population } \\
\text { (millions) }\end{array}$ & $\begin{array}{l}\text { Life } \\
\text { expectancy (at } \\
\text { birth) }\end{array}$ & $\begin{array}{l}\text { \% of total } \\
\text { mortality } \\
\text { attributed to } \\
\text { CHD }\end{array}$ & $\begin{array}{l}\text { Per capita GNI } \\
\text { PPP\$ }\end{array}$ \\
\hline Tunisia & 10.1 & 74 & $27.14 \%$ & 6,820 \\
Syria & 18.9 & 75 & $34.25 \%$ & 4,010 \\
Palestine (oPt) & 3.8 & 72 & $21.98 \%$ & $2,710 *$ \\
Turkey & 70 & 74 & $18.66 \%$ & 11,330 \\
\hline
\end{tabular}

Footnotes: GNI per capita PPP\$ is Gross National Income in PPP US \$

Sources: Arab Human Development Report 2009. UNDP, HDR 2007/2008 for Tunisia, Syria and oPt (data for 2005). Turkey Statistical Institute for Turkish data (2007).

Per capita GNI from World Bank Development Indicators (UN data, 2005).

Life expectancy from World Bank

http://www.indexmundi.com/facts/indicators/SP.DYN.LE00.IN/compare?country=sy.

Proportion of all deaths from CHD http://vizhub.healthdata.org/gbd-compare/ (year 2010) 
Table 2:Crude CHD mortality rates and trends in the four Eastern Mediterranean countries

\begin{tabular}{|c|c|c|c|c|c|c|c|c|c|c|}
\hline \multirow{2}{*}{$\begin{array}{l}\text { Country } \\
\text { (years) }\end{array}$} & \multirow{3}{*}{$\begin{array}{l}\text { Sex } \\
\text { Total }\end{array}$} & \multicolumn{2}{|c|}{$\begin{array}{c}\text { Population } \\
(, 000)\end{array}$} & \multirow{2}{*}{$\begin{array}{l}\text { Number } \\
\text { of deaths } \\
\text { Initial }\end{array}$} & \multirow{2}{*}{$\begin{array}{l}\text { Rate/ } \\
10^{5} \\
\\
\text { year }\end{array}$} & \multirow{2}{*}{$\begin{array}{l}\text { Number } \\
\text { of deaths } \\
\text { Final }\end{array}$} & \multirow{2}{*}{$\begin{array}{l}\text { Rate/ } \\
10^{5} \\
\\
\text { year }\end{array}$} & \multirow{2}{*}{$\begin{array}{l}\text { \% } \\
\text { change } \\
\text { in } \\
\text { rate }\end{array}$} & \multirow{2}{*}{$\begin{array}{l}\text { \% change in } \\
\text { directly age- } \\
\text { standardised } \\
\text { rate }^{\$} \\
\text { [annual change\%] }\end{array}$} & \multirow{2}{*}{$\begin{array}{l}\text { Observed } \\
\text { increase } \\
\text { or } \\
\text { decrease } \\
\text { in deaths* }\end{array}$} \\
\hline & & $\begin{array}{l}\text { Initial } \\
\text { Year }\end{array}$ & $\begin{array}{l}\text { Final } \\
\text { year }\end{array}$ & & & & & & & \\
\hline Tunisia & & 4301 & 5700 & 2106 & 49 & 3633 & 64 & +30 & $\begin{array}{l}+20 \\
{[+1.7 \%} \\
\text { p.a.] }\end{array}$ & +682 \\
\hline \multirow{2}{*}{$\begin{array}{l}(1997- \\
2009)\end{array}$} & Men & 2126 & 2789 & 1492 & 70 & 2429 & 87 & +24 & & +332 \\
\hline & Women & 2176 & 2911 & 614 & 28 & 1205 & 41 & +47 & & +350 \\
\hline Syria & Total & 5013 & 7410 & 5429 & 108 & 12503 & 169 & +56 & $\begin{array}{l}+62 \\
{[+6.2 \%} \\
\text { p.a.] }\end{array}$ & +6372 \\
\hline \multirow{2}{*}{$\begin{array}{l}(1996- \\
2006)\end{array}$} & Men & 2538 & 3735 & 3608 & 142 & 8119 & 217 & +53 & & +3772 \\
\hline & Women & 2475 & 3675 & 1821 & 73 & 4384 & 119 & +62 & & +2660 \\
\hline \multirow[t]{3}{*}{$\begin{array}{l}\text { oPt } \\
(1998 \text { - } \\
2009)\end{array}$} & Total & 610 & 913 & 520 & 85 & 586 & 64 & -25 & $\begin{array}{l}-17 \\
{[-1.5 \%} \\
\text { p.a.] }\end{array}$ & -122 \\
\hline & Men & 302 & 461 & 318 & 105 & 394 & 86 & -19 & & -60 \\
\hline & Women & 308 & 452 & 202 & 66 & 192 & 43 & -35 & & -62 \\
\hline \multirow[t]{3}{*}{$\begin{array}{l}\text { Turkey } \\
(1995- \\
2008)\end{array}$} & Total & 18932 & 27958 & 79066 & 418 & 96366 & 345 & -17 & $\begin{array}{l}-29 \\
{[-2.2 \%} \\
\text { p.a.] }\end{array}$ & $-35,718$ \\
\hline & Men & 9418 & 13655 & 42938 & 456 & 49910 & 366 & -20 & & $-17,162$ \\
\hline & Women & 9514 & 14303 & 36128 & 379 & 46457 & 324 & -14 & & $-18,556$ \\
\hline
\end{tabular}

Footnotes: 
${ }^{\$} \mathrm{CHD}$ mortality rates for ages 35-74 (this age range chosen to be consistently available from all 4 populations), standardised to the World Standard Population.

*This figure represents the observed change in mortality using indirect standardisation i.e. after accounting for changes in the age-sex structure of the population over time. This is the change in deaths which the model then attempts to explain. It applies only to the final year of the period (2006 in Syria, 2008 in Turkey, 2009 in oPt and Tunisia. 
Table 3: Risk factor trends and consequent mortality changes in the four Eastern Mediterranean countries (men \& women combined)

\begin{tabular}{|c|c|c|c|c|c|c|c|c|c|}
\hline \multirow[b]{2}{*}{ Country } & \multirow[t]{2}{*}{ Risk Factor } & & \multicolumn{2}{|c|}{ Prevalence } & \multirow{2}{*}{$\begin{array}{l}\text { Absolute } \\
\text { change in } \\
\text { risk factor* }\end{array}$} & \multicolumn{3}{|c|}{$\begin{array}{c}\text { Changes in deaths (increases or } \\
\text { decreases) }\end{array}$} & \multirow{2}{*}{$\begin{array}{c}\% \text { of total } \\
\text { mortality } \\
\text { trend }\end{array}$} \\
\hline & & & Initial year & Final year & & Estimated & Min & Max & \\
\hline $\begin{array}{l}\text { Tunisia } \\
\text { (1997-2009) }\end{array}$ & $\begin{array}{l}\text { Smoking } \\
\text { SBP }(\mathrm{mmHg}) \\
\text { Cholesterol (mmol/l) } \\
\text { BMI }\left(\mathrm{kg} / \mathrm{m}^{2}\right) \\
\text { Diabetes \% } \\
\text { Physical inactivity\% }\end{array}$ & Total & $\begin{array}{c}23.9 \\
130.4 \\
4.59 \\
26.0 \\
12.1 \\
98\end{array}$ & $\begin{array}{c}22.7 \\
131.0 \\
4.73 \\
27.5 \\
17.3 \\
85\end{array}$ & $\begin{array}{l}-1.2 \\
+0.60 \\
+0.14 \\
+1.44 \\
+5.2 \\
-13\end{array}$ & $\begin{array}{l}-14 \\
+166 \\
+273 \\
+86 \\
+62 \\
-35 \\
+538\end{array}$ & $\begin{array}{c}-53 \\
+20 \\
+204 \\
+60 \\
+4 \\
-48 \\
+368\end{array}$ & $\begin{array}{c}24 \\
+350 \\
+384 \\
+112 \\
+123 \\
-23 \\
+777\end{array}$ & $\begin{array}{c}-2.1 \\
+24.3 \\
+40.0 \\
+12.6 \\
+9.2 \\
-5.1 \\
+\mathbf{+} 78.9 \%\end{array}$ \\
\hline $\begin{array}{l}\text { Syria } \\
(1996-2006)\end{array}$ & $\begin{array}{l}\text { Smoking } \\
\text { SBP (Systolic BP) } \\
\text { Cholesterol } \\
\text { BMI } \\
\text { Diabetes } \\
\text { Physical inactivity\% }\end{array}$ & Total & $\begin{array}{c}33 \\
122.2 \\
5.05 \\
28.0 \\
9 \\
-\end{array}$ & $\begin{array}{c}37 \\
130.9 \\
5.34 \\
29.7 \\
13 \\
-\end{array}$ & $\begin{array}{c}+4 \\
+8.7 \\
+0.29 \\
+1.8 \\
+4 \\
-\end{array}$ & $\begin{array}{c}+171 \\
+2073 \\
+1348 \\
+373 \\
+636 \\
- \\
+4601\end{array}$ & $\begin{array}{l}-216 \\
+1209 \\
+1006 \\
+266 \\
+242 \\
- \\
+3428\end{array}$ & $\begin{array}{c}+549 \\
+3576 \\
+1508 \\
+479 \\
+1013 \\
- \\
+6186\end{array}$ & $\begin{array}{c}+2.7 \\
+32.5 \\
+21.2 \\
+5.9 \\
+10.0 \\
- \\
+72.2 \%\end{array}$ \\
\hline $\begin{array}{l}\text { oPt (West Bank) } \\
(1998-2009)\end{array}$ & $\begin{array}{l}\text { Smoking } \\
\text { SBP (Systolic BP) } \\
\text { Cholesterol } \\
\text { BMI } \\
\text { Diabetes \% } \\
\text { Physical inactivity\% }\end{array}$ & . & $\begin{array}{c}32 \% \\
121.4 \\
5.0 \\
28.0 \\
9 \\
84\end{array}$ & $\begin{array}{c}22 \% \\
121.3 \\
4.94 \\
31.0 \\
12 \\
92\end{array}$ & $\begin{array}{l}-10 \\
-0.10 \\
-0.06 \\
+3 \\
+3 \\
+8\end{array}$ & $\begin{array}{l}-29 \\
-33 \\
-39 \\
+2 \\
+28 \\
+16 \\
-56\end{array}$ & $\begin{array}{l}-78 \\
-235 \\
-140 \\
-23 \\
-16 \\
+8 \\
-160\end{array}$ & $\begin{array}{l}+11 \\
155 \\
46 \\
+28 \\
+71 \\
+17 \\
+294\end{array}$ & $\begin{array}{c}-23.7 \\
-27.3 \\
-32.3 \\
+1.7 \\
+22.7 \\
+10 \\
-45.7 \%\end{array}$ \\
\hline $\begin{array}{l}\text { Turkey } \\
(1995-2008)\end{array}$ & $\begin{array}{l}\text { Smoking\% } \\
\text { SBP } \\
\text { Cholesterol } \\
\text { BMI } \\
\text { Diabetes \% } \\
\text { Physical inactivity\% }\end{array}$ & Total & $\begin{array}{c}27 \\
127.2 \\
4.96 \\
27.4 \\
15.5 \\
70\end{array}$ & $\begin{array}{c}16 \\
124.6 \\
4.97 \\
29.0 \\
18.7 \\
65\end{array}$ & $\begin{array}{c}-11 \\
-2.6 \\
+0.01 \\
+1.6 \\
+3.2 \\
-5\end{array}$ & $\begin{array}{c}-8423 \\
-8723 \\
+310 \\
+3310 \\
+4456 \\
-1683 \\
-10763\end{array}$ & $\begin{array}{l}-10205 \\
-12453 \\
-2238 \\
+2783 \\
+2236 \\
-2418 \\
-16191\end{array}$ & $\begin{array}{l}-6679 \\
-4763 \\
+2797 \\
+3878 \\
+6651 \\
-1085 \\
-4955\end{array}$ & $\begin{array}{c}-23.6 \\
-24.4 \\
+0.9 \\
+9.3 \\
+12.5 \\
-4.7 \\
-30.1 \%\end{array}$ \\
\hline
\end{tabular}

*Footnote: A positive value denotes an increase in the risk factor and an increase in deaths attributed to the risk factor increase. A negative value denotes a decrease in the risk factor and a consequent decrease in deaths attributed to the risk factor. Physical activity data not available from Syria. Individual rows may not sum to their subtotals due to rounding. 
Table 4a: Treatment contributions: numbers of patients in specific groups and CHD deaths prevented or postponed in Tunisia and Syria where CHD mortality was rising (men and women combined)

\begin{tabular}{|c|c|c|c|c|c|c|c|c|}
\hline \multirow[t]{2}{*}{ Country } & \multirow[t]{2}{*}{ Treatment group } & \multirow[t]{2}{*}{$\begin{array}{l}\text { Eligible } \\
\text { Patients }\end{array}$} & \multicolumn{3}{|c|}{$\begin{array}{l}\text { Deaths prevented } \\
\text { or postponed } \\
\text { (estimates) }\end{array}$} & \multicolumn{3}{|c|}{$\begin{array}{c}\text { Estimated \% } \\
\text { reduction in CHD } \\
\text { mortality attributed } \\
\text { to treatments }\end{array}$} \\
\hline & & & Best & (Min) & (Max) & Best & (Min) & (Max) \\
\hline \multirow[t]{10}{*}{ Tunisia } & Acute Myocardial Infarction (AMI) & 4505 & 89 & 78 & 101 & 7.8 & 6.9 & 8.9 \\
\hline & Unstable Angina & 6755 & 77 & 67 & 88 & 6.8 & 5.9 & 7.8 \\
\hline & Secondary Prev Post AMI & 24058 & 95 & 87 & 103 & 8.4 & 7.7 & 9.1 \\
\hline & Secondary Prev Post CABG/PCI & 1300 & 3 & 2 & 3 & 0.3 & 0.2 & 0.3 \\
\hline & Chronic Angina & 53436 & 0 & -19 & 15 & 0.0 & -1.7 & 1.3 \\
\hline & Hospital Heart Failure & 3614 & 37 & 22 & 55 & 3.3 & 2.0 & 4.9 \\
\hline & Community Heart Failure & 25298 & 49 & 43 & 55 & 4.3 & 3.8 & 4.9 \\
\hline & Hypertension Treatment & 1496744 & 80 & 38 & 138 & 7.1 & 3.4 & 12.2 \\
\hline & Statins primary prevention & 601743 & 21 & 18 & 24 & 1.9 & 1.6 & 2.1 \\
\hline & Total $^{*}$ & & 448 & 376 & 530 & 39.7 & 33.2 & 46.9 \\
\hline \multirow[t]{10}{*}{ Syria } & Acute Myocardial Infarction (AMI) & 18002 & 287 & 250 & 321 & 3.4 & 2.9 & 3.8 \\
\hline & Unstable Angina & 22877 & 150 & 142 & 158 & 1.8 & 1.7 & 1.9 \\
\hline & Secondary Prev Post AMI & 78976 & 372 & 280 & 481 & 4.4 & 3.3 & 5.7 \\
\hline & Secondary Prev Post CABG/PCI & 26316 & 65 & 46 & 84 & 0.8 & 0.5 & 1.0 \\
\hline & Chronic Angina & 319974 & 803 & 638 & 1013 & 9.4 & 7.5 & 11.9 \\
\hline & Hospital Heart Failure & 6927 & 84 & -9 & 168 & 1.0 & -0.1 & 2.0 \\
\hline & Community Heart Failure & 52251 & 332 & 279 & 376 & 3.9 & 3.3 & 4.4 \\
\hline & Hypertension Treatment & 863425 & 45 & 17 & 78 & 0.5 & 0.2 & 0.9 \\
\hline & Statins primary prevention & 307295 & 6 & 4 & 10 & 0.1 & 0.0 & 0.1 \\
\hline & Total $^{*}$ & & 2145 & 1648 & 3170 & 25.2 & 23.0 & 27.4 \\
\hline
\end{tabular}

Footnotes:

The denominator is the estimated total number of $\mathrm{CHD}$ deaths in the absence of any treatments i.e. Tunisia $1130(680+450)$ and Syria $8515(6370+2145)$.

For Tunisia, chronic angina treatment in the community (best estimate) is zero since aspirin use was already high in the model base year (1997), and hence there was little scope for increase over time.

*The totals row does not represent the sum of each treatment component due to the bootstrap methodology.

KEY:

$\mathrm{AMI}=$ Acute myocardial infarction

CABG = Coronary artery bypass graft surgery

$\mathrm{PCl}=$ Percutaneous intervention 
Table 4b: Treatment contributions: numbers of patients in specific groups and CHD deaths prevented of postponed in the oPt and Turkey where CHD mortality was falling (men and women combined)

\begin{tabular}{|c|c|c|c|c|c|c|c|c|}
\hline \multirow[t]{2}{*}{ Country } & \multirow[t]{2}{*}{ Treatment group } & \multirow[t]{2}{*}{$\begin{array}{l}\text { Eligible } \\
\text { Patients }\end{array}$} & \multicolumn{3}{|c|}{$\begin{array}{l}\text { Deaths prevented } \\
\text { or postponed } \\
\text { (estimates) }\end{array}$} & \multicolumn{3}{|c|}{$\begin{array}{l}\% \text { of the mortality } \\
\text { change explained }\end{array}$} \\
\hline & & & Best & (Min) & $(\operatorname{Max})$ & Best & (Min) & $(\operatorname{Max})$ \\
\hline \multirow{10}{*}{ oPt } & Acute Myocardial Infarction (AMI) & 489 & 2 & 2 & 2 & 1.9 & 1.3 & 1.7 \\
\hline & Unstable Angina & 489 & 1 & 1 & 1 & 1.1 & 1.0 & 1.2 \\
\hline & Secondary Prev Post AMI & 2266 & 8 & 6 & 10 & 7.3 & 5.0 & 8.6 \\
\hline & Secondary Prev Post CABG/PCI & 1974 & 2 & 2 & 3 & 1.9 & 1.5 & 1.9 \\
\hline & Chronic Angina*** & 22180 & 10 & 9 & 11 & 8.4 & 7.2 & 8.8 \\
\hline & Hospital Heart Failure & 468 & 2 & 2 & 3 & 1.5 & 1.5 & 2.1 \\
\hline & Community Heart Failure & 2342 & 7 & 5 & 8 & 5.3 & 4.5 & 6.2 \\
\hline & Hypertension Treatment & 81894 & 5 & 4 & 6 & 4.1 & 3.1 & 6.2 \\
\hline & Statins primary prevention & 7030 & 0 & 0 & 0 & 0 & 0 & 0.0 \\
\hline & \multicolumn{2}{|l|}{ Total } & 38 & 29 & 46 & 31.5 & 23.4 & 37.7 \\
\hline \multirow[t]{10}{*}{ Turkey } & Acute Myocardial Infarction (AMI) & 91317 & 1677 & 1448 & 1930 & 4.7 & 4.1 & 5.4 \\
\hline & Unstable Angina & 45658 & 638 & 562 & 722 & 1.8 & 1.6 & 2.0 \\
\hline & Secondary Prev Post AMI & 759071 & 4570 & 4100 & 5088 & 12.8 & 11.5 & 14.2 \\
\hline & Secondary Prev Post CABG/PCI & 273379 & 1752 & 1401 & 2160 & 4.9 & 3.9 & 6.0 \\
\hline & Chronic Angina*** & 103293 & 2622 & 2046 & 3265 & 7.3 & 5.7 & 9.1 \\
\hline & Hospital Heart Failure & 46511 & 1025 & 891 & 1144 & 2.8 & 2.5 & 3.2 \\
\hline & Community Heart Failure & 424511 & 2338 & 2074 & 2632 & 6.5 & 5.8 & 7.4 \\
\hline & Hypertension Treatment & 10553133 & 2153 & 1899 & 2427 & 6.0 & 5.3 & 6.8 \\
\hline & Statins primary prevention & 4483287 & 41 & 32 & 53 & 0.1 & 0.1 & 0.1 \\
\hline & \multicolumn{2}{|l|}{ Total } & 16794 & 16026 & 17598 & 47.0 & 44.9 & 49.3 \\
\hline
\end{tabular}

KEY:

AMI = Acute myocardial infarction

CABG = Coronary artery bypass graft surgery

$\mathrm{PCl}=$ Percutaneous intervention 